\title{
Review of: "Why is vertebral pneumaticity in sauropod dinosaurs so variable?"
}

\author{
Fernando E. Novas
}

Potential competing interests: The author(s) declared that no potential competing interests exist.

I congratulate the authors for clarifying interesting aspects of postcranial pneumatization in sauropods, in particular, and archosaurs, in general. I like the clear way they exposed their ideas, and in being respectful for observations and interpretations expressed by previous authors, especially those in old contributions. Particularly clarifying is the recognition that the paired foramina or fossa existing on both sides of the neural canal in different archosaurian groups may explained as mirroring the same pattern of development of the circulatory system. Authors also offer good explanations of postcranial pneumaticity based on embryological and ontogenetic development of living reptiles.

Authors ask: "Why did pneumatization favour the neural arches over the centra in these cases? If pneumatization was governed by simple proximity to the lungs and air sacs, the centra should have been pneumatized first. But since developing diverticula followed the large segmental arteries that serve the spinal cord..... I agree with their observations and conclusion, of course, but I will suggest modify this phrase for the following one: "Why did pneumatization favour the neural arches over the centra in these cases? Because developing diverticula follow the large segmental arteries that serve the spinal cord". The reasons for this change in the phrasing (and reasoning) is that in living birds the lungs are adpressed against both centra and ventral surface of transverse processes of thoracic vertebrae, thus no difference in distance exists between these two vertebral components and the surrounding lungs/air sacs. Second, neck and tail are also pneumatized, but these parts of the body are far from the lungs.

Some minor grammatical modifications are required:

1. Authors say: “...then as the notochord segments and is replaced by the cartilaginous anlagen...", must be replaced for

"...then as the notochord segments are replaced by the cartilaginous anlagen..."

2. Authors say: “...in Giraffatitan extensive caudal pneumaticity in present only in large individuals...” Modify for: "in Giraffatitan extensive caudal pneumaticity is present only in large individuals..."

3. Delete the word "then" repeated in the phrase: "... If our hypothesis that pneumatization follows vascularization is correct, then then this could..."

Sincerely,

Fernando Novas 